\title{
REVIEWS
}

J. R. LeMaster and Donald D. Kummings, eds. Walt Whitman: An Encyclopedia. New York: Garland, 1998. xxxiii +847 pp.

The work of more than two hundred contributors and encompassing more than 750 entries on Whitman, his work, and his world, Walt Whitman: An Encyclopedia is, as its editors claim (ix), a reference work so comprehensive as to have no true precedent for readers of Whitman. In fact, it seems likely to become a standard Whitman reference source.

Its contents are very nearly exhaustive. They include entries on all major and most minor Whitman poems, all clusters, all editions of Leaves of Grass and of the various prose works, all known early short stories, and all of his long and many of his short works of prose nonfiction. They include entries on many of his friends, relatives, and contemporary as well as predecessor artists and writers. In recognition of his extraordinary influence on international culture, they include analyses of Whitman's reception in all inhabited continents and in dozens of countries around the world. A sign of a mature historiographical tradition running nearly one hundred fifty years, they even include entries on Whitman critics of the nineteenth and twentieth centuries. Nicely rounding out the volume is a chronology preceding the encyclopedia proper and a genealogy following it (both professionally done by William Pannapacker) and a fairly generous selection of illustrations (if dominated in general by familiarity). A thorough index, as well as a brief bibliography and cross-referential list of related topics following each entry, increases the volume's usefulness.

The coverage is not only comprehensive but astute. The editors have knowingly and intelligently covered the primary and secondary bases of Whitman studies: nationalism and internationalism, textual history and bibliography, style and substance, religion and secularism, high and popular culture, letters and related media, race and gender. In attempting to secure the fullest and most balanced coverage, they have invited contributions from a wide variety of scholars representing three generations. The contributors include many of the leading Whitman scholars of our time, to whom the editors have deferred in various cases for major entries, such as Ed Folsom on photography, David Reynolds on popular culture, Jerome Loving on Whitman biographies, Sherry Ceniza on women supporters and women's rights, Alice Birney on Whitman collections and collectors; and to them and others simply for treatment of a wide-ranging variety of subjects. But they have equally drawn on the rising generation of younger scholars and graduate students likely to bring Whitman studies well into the twenty-first century. Although errors of fact and lapses of judgment inevitably creep in, the overall accuracy and critical reliability of the volume are as good as one could wish for and expect.

As to the underlying character of the entries, the operating editorial principle seems - predictably - to favor solidity and accuracy over novelty and original- 
ity, a principle that seems to me the right one in a volume likely to become a standard reference work. It sacrifices new insights - of which there are few- to consolidation of the work of earlier scholars and critics. It generally avoids issues posed by critical theory. It also generally avoids polemics. Although there are instances of obvious generational and ideological differences over such matters as critical taste and practice and Whitman's radicalism/conservatism (on which George Hutchinson is particularly sound), an inevitability when drawing on a broad spectrum of contributors writing in critically fractious times, the editors have managed by and large to preserve a loose critical and practical harmony without overreaching for consensus.

As a consequence of this editorial policy, the volume is in general intellectually conservative, despite the fact that it is broadly conscious of the national and academic politics of the last generation in its solicitude toward changing ideas about race, gender, and ethnicity. One exception is Walter Grünzweig's suggestive entry on "interculturality," which, as he knows, draws on the internationalism strand already well developed and likely to grow stronger in Whitman criticism. Another is Kummings's good but underdeveloped entry on "Whitman on the internet," which mentions but does not delve into the pathbreaking Walt Whitman Hypertext Archive currently under construction by Ed Folsom and Kenneth Price. That project, like the equally monumental Emily Dickinson Electronic Archive overseen by Martha Nell Smith, has profound implications for the future of literary studies, raising complicating, comparativist issues of textuality, evidence, mediacy, and sequentiality meaningful to the study of literary culture in general but bearing a particular relevance to the medium-conscious poetry of Leaves of Grass and its convoluted textual history. For that matter, it also complicates the status of the Encyclopedia itself.

The Encyclopedia is clearly a reflection, as I have suggested, of a state of maturity in Whitman studies, but it is also itself a significant contribution to that corpus of work - to which, to invoke a Whitmanism, it adds "sinew." This is a volume that both institutions and individual scholars will wish to have on their Whitman bookshelves, where they will soon find it an indispensable resource.

\section{University of South Carolina}

EzRa GreEnspan

JoAnn P. Krieg. $A$ Whitman Chronology. Iowa City: University of Iowa Press, 1998. xxii +207 pp.

When and where did Whitman first meet William O'Connor? How long before the appearance of Leaves of Grass did he publish his first poem? How many times did Whitman attend operas by Gaetano Donizetti, and which ones did he see? To anyone who has ever confronted the need to know such details of Whitman's biography, perhaps in the heat of writing an article or lecture, the usefulness of a one-volume chronology must be immediately apparent. With the facts of Whitman's life now spread across at least five biographies, seven volumes of correspondence, nine volumes of conversations with Horace Traubel, and nine more of notebooks and manuscripts, a shortcut to what is known is almost indispensable. 